\title{
IN VITRO STUDIES OF TRANSPLANTATION ANTIGENS PRESENT ON BONE CELLS IN THE RAT
}

\author{
Domingo luis Muscolo, Buenos Aires, Argentina, Shinya Kawai, Ube, Japan and \\ Robert D. Ray, Chicago, United States of America
}

From the Department of Orthopaedic Surgery, Abraham Lincoln School of Medicine, The University of Illinois

In vitro studies on isolated bone cells were undertaken to investigate the presence of transplantation (histocompatibility) antigens. Bone cells were cultured with allogeneic lymphocytes and exposed to cytotoxic sera containing antibodies against transplantation antigens, to determine their antigenic profile. Preliminary results suggest that bone cells may not express lymphocyte stimulating antigens in an active form, at least after the isolation procedure performed. On the other hand, bone cells were killed by cytotoxic antibodies in a specific way, providing evidence for the presence of serologically defined (SD) transplantation antigens on the cell surface. Additional studies with absorbed sera suggest "sharing" of histocompatibility antigens between bone cells and lymphocytes. The relevance of the surface antigens of bone cells to clinical fields such as bone allotransplantation, susceptibility to various orthopaedic diseases and skeletal sarcomata is discussed.

Although much attention has been focused upon the antigenicity of bone homogenates and/or allografts, there are no reports on the antigenic components of bone cells. Antigenic structures on bone cell membranes have not been isolated from the great number of potential antigens present in bone that generate immune responses.

Cell surface antigens seem to play a key role in different biological phenomena (Bach, Bach and Sondel 1976), and it is likely that attempts to define those antigens on bone cells could be relevant to clinical situations such as bone allotransplantation (Ottolenghi 1972; Muscolo, Kawai and Ray 1976), immunological management of skeletal sarcomas (Invernizzi and Parmiani 1975), and possible susceptibility to some orthopaedic diseases (McDevitt and Bodmer 1974), and they might also help in clarifying the aetiology of those orthopaedic disorders suspected of being related to auto-immunity.

The present study was undertaken to investigate the presence of major transplantation (histocompatibility) antigens on bone cells. Isolated bone cells were cultured in vitro with allogeneic lymphocytes (from genetically disparate individuals within the same species) to determine if they carry antigens capable of stimulating lymphocytes. Also bone cells were exposed to cytotoxic antiserum, containing antibodies against major transplantation antigens, in order to study their antigenic profile.

\section{Rats}

\section{MATERIALS AND METHODS}

Lewis, Brown-Norway (BN), Fisher and Buffalo adult male rats were purchased from Microbiological Associates, Bethesda, Maryland. These strains of rats are highly inbred and each, with the exception of Lewis and Fisher, differs from the others at the major histocompatibility locus of the rat Ag-B - the equivalent of human HL-A (Palm 1971).

\section{Isolation of bone cells}

The technique previously described by Bard, Dickens, Edwards and Smith (1974) was used with minor modifications. Soft tissues, periosteum and cartilage were removed from femora and tibiae and the marrow was removed by washing with TC medium 199 (Difco, Detroit, Michigan).

Bone slices of approximately 150 micrometres were cut under continuous irrigation using a thin sectioning machine (Bronwill-Gillings, Rochester, New York) fitted with a diamond impregnated blade. The slices were dipped into distilled sterile water for two seconds in order to lyse any remaining marrow cells, and transferred to flasks containing 1.5-1.7 per cent dipotassium salt of EDTA and 5 per cent heat inactivated (56 degrees Celsius for thirty minutes) autologous serum in 20 millilitres of TC medium 199. The flasks were gassed with 5 per cent $\mathrm{CO}_{2}$ in air, sealed, and shaken in water bath at 37 degrees Celsius for eighteen hours.

After decalcification, the slices were washed, resuspended in flasks containing 2-3 milligram of collagenase (Sigma Type I, 150 units $/ \mathrm{mg}$ ) in 10 millilitres of medium, and shaken for two hours or more until they were completely digested. The isolated bone cells were washed twice and viability determined by the trypan blue exclusion test (usually 60-70 per cent). The cell concentiation was determined by haemocytometer and phase contrast microscopy (normally $8 \times 10^{5} \times \mathrm{ml}$ ).

The isolated cells showed multiple delicate processes (Fig. 3) or were bipolar with long unbranched processes as previously described.

\section{Cellular in vitro experiments}

When two populations of lymphoid cells from individuals genetically different at the major histocompatibility locus are cultured together in vitro, an interaction between the cells takes place and lymphocyte proliferation occurs. This reaction, called mixed lymphocyte culture (MLC), reflects antigenic differences between the cells. In the present experiments, mixed lymphocyte-bone cell cultures (MLBCC) were established to determine if bone cells are capable of stimulating lymphocyte proliferation when cultured together in vitro.

With that purpose in mind the following cultures were established (Fig. 1): 1) lymphocytes from Lewis rats +lym-

Domingo Luis Muscolo, M.D.. Institute of Orthopaedics and Traumatology, Italian Hospital. L'niversity of Buenom Aires, Potosi 4215 , Buenos Aires. Argentina.

Shinya Kawai, M.D.. Department of Orthopaedic Surgery. Yamaguchi University, School of Medicine. Uhe (ity. 7555 Japan.

Robert D. Ray. M.D.. Ph.D.. Department of Orthopaedic Surgery, University of Illinois, $8+0$ South Wood Street, (hicage, Illinois 606/2. U.S.A.

Requests for reprints should be addressed to Dr Muscolo. 


\section{CELLULAR EXFERIMENTS}

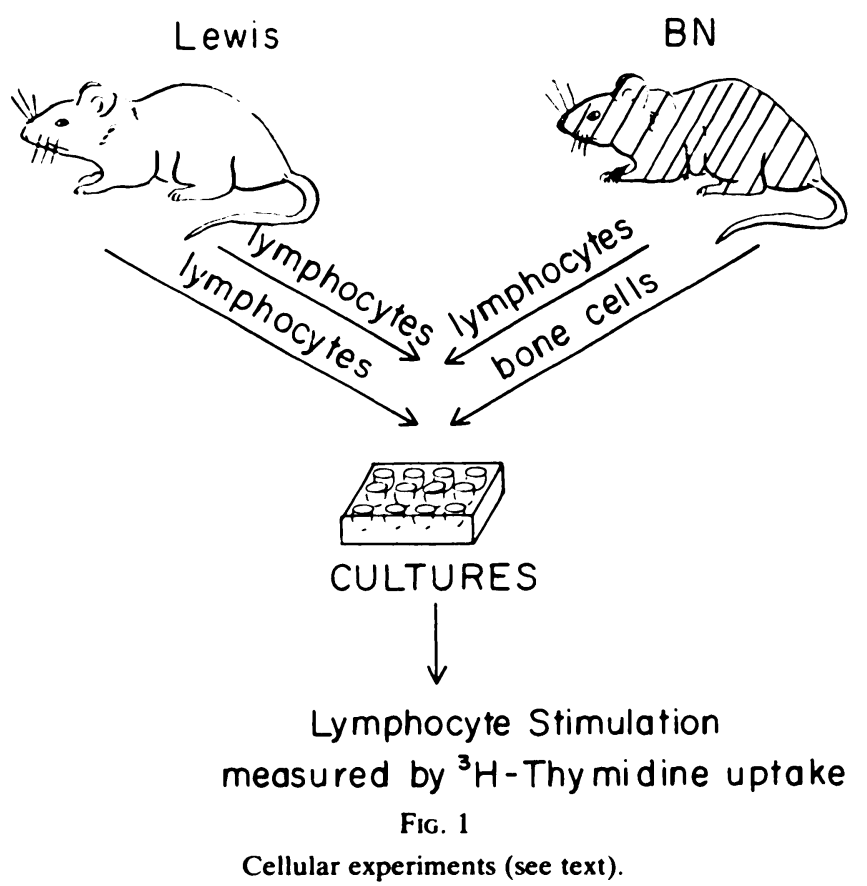

phocytes from BN rats (MLC), and 2) lymphocytes from Lewis rats + bone cells from BN rats (MLBCC). Since there are major histocompatibility differences between Lewis and BN rats, mixed lymphocyte cultures will give rise to high stimulation. The results were compared with those obtained in mixed lymphocyte-bone cell cultures.

The following cultures served as controls: 1) lymphocytes + lymphocytes or bone cells from the same rat strain (no histocompatibility differences and, therefore, no anticipated stimulation); and 2) lymphocytes from Lewis rats + lymphocytes from $\mathrm{BN}$ rats + bone cells from $\mathrm{BN}$ rats to determine possible inhibitory effects of bone cells over regular mixed lymphocyte cultures.

Mixed lymphocyte culture (MLC) and mixed lymphocyte-bone cell culture techniques (MLBCC)-The culture procedure has been fully described elsewhere (Muscolo et al. 1976). Blood was collected by cardiac puncture and lymphocyte suspensions were prepared by dextran sedimentation. After washing, the lymphocytes were resuspended in culture medium (supplemented MEM Hank's base with 10 per cent heat inactivated rat serum) and a cell suspension of $2.5 \times 10^{6} \times \mathrm{ml}$ (85 per cent living lymphocytes) was prepared. The cells were mixed and cultured in 0.2 millilitre microplates. After 120 hours of incubation at 37 degrees Celsius in humidified 5 per cent $\mathrm{CO}_{2}$ air atmosphere, $1 \mu \mathrm{Ci}$ of ${ }^{3} \mathrm{H}$-Thymidine (Sp. ac 6.7 $\mathrm{Ci} / \mathrm{Mmole}$ ) was added to each culture. Eighteen hours later, the cultures were precipitated onto glass fibre paper and the lymphocyte proliferation assayed by determining the ${ }^{3} \mathrm{H}$ Thymidine uptake using liquid scintillation spectrometry.

Varying concentrations of bone cells were used in the MLBCC, ranging from 0.4 to $1.2 \times 10^{6} \times \mathrm{ml}$.

The results were expressed as the mean count per minute ( \pm standard error) of four replicate cultures.

Humoral experiments (Fig. 2)

Immunisation of animals-Twenty Lewis rats were grafted with complete bone (cortex and marrow) or bone free of marrow (cortex minus marrow) from $B N$ rats. The bones
HUMORAL EXPERIMENTS

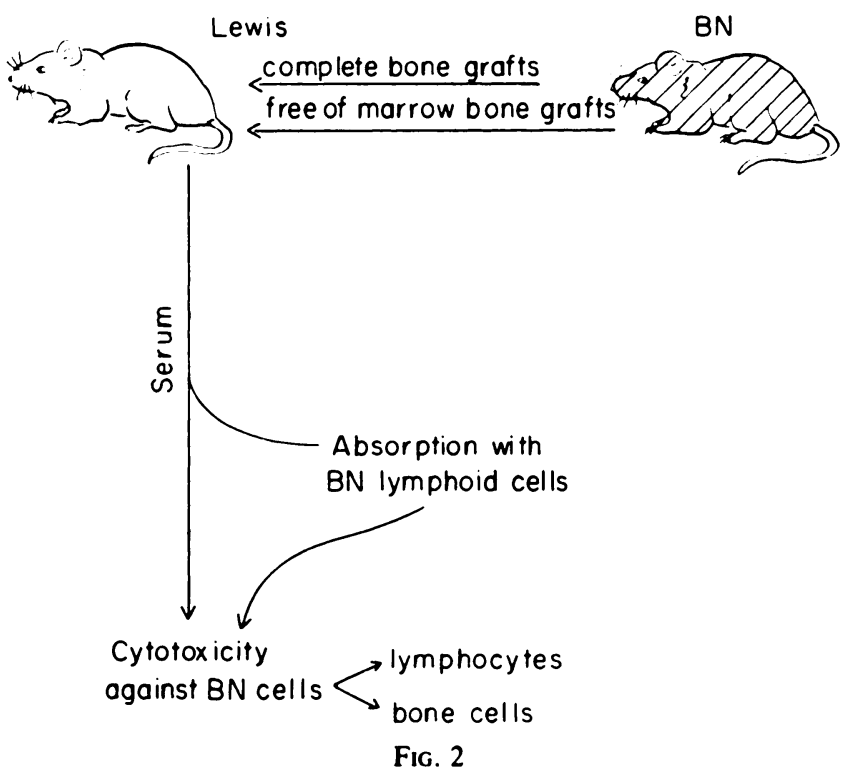

Humoral experiments (see text).

were split into pieces and grafted into the subcutaneous tissues in both flanks.

Humoral cytotoxicity studies-At intervals after immunisation, serum was obtained from the immunised Lewis rats and studied for the presence of cytotoxic antibodies in the trypan blue exclusion cytotoxicity test (Tissot and Cohen 1972), using lymphocytes and isolated bone cells from BN rats as target cells. The principle of the cytotoxic test is as follows: target cells, serum and complement are incubated in vitro; if the serum contains antibodies against major histocompatibility antigens on the target cell surface, complement is fixed and the cell dies. The percentage of killed cells is then determined by trypan blue uptake. Dead cells are stained by trypan blue, viable cells are not (Figs. 3 to 5).

Results were expressed as cytotoxicity index:

$$
\frac{\text { sample - control }}{100-\text { control }} \times 100
$$

The mean cytotoxic percentage obtained with sera from five Lewis rats grafted with bone from Lewis or Fisher rats (with no major histocompatibility differences; not included in Figure 2) tested against lymphocytes or bone cells from BN rats (4 per cent and 41 per cent cytotoxicity respectively) served as control values. Significance levels were calculated by the Student's t test.

Absorption studies (Fig. 2)-Absorption is the removal of antibody from an immune serum by treatment with particulate antigen homologous to that antibody, followed by centrifugation and separation of the antigen-antibody complex.

Serum obtained from Lewis rats grafted with bone from $B N$ rats was divided in two groups: one was untreated, a second was absorbed with BN lymphoid cells. The cytotoxic activity of both serum groups was then tested against lymphocytes and bone cells from BN rats as described.

The purpose of this part of the experiment was to determine if lymphocytes and bone cells share surface antigens. If so, both should show none or at least diminished cytotoxicity when tested with the absorbed sera. 


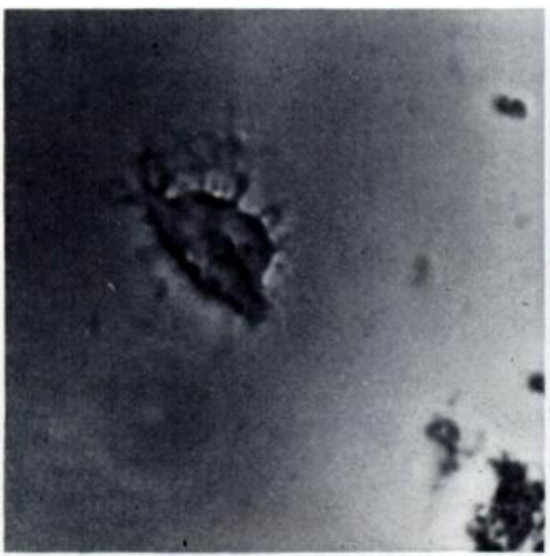

Fig. 3

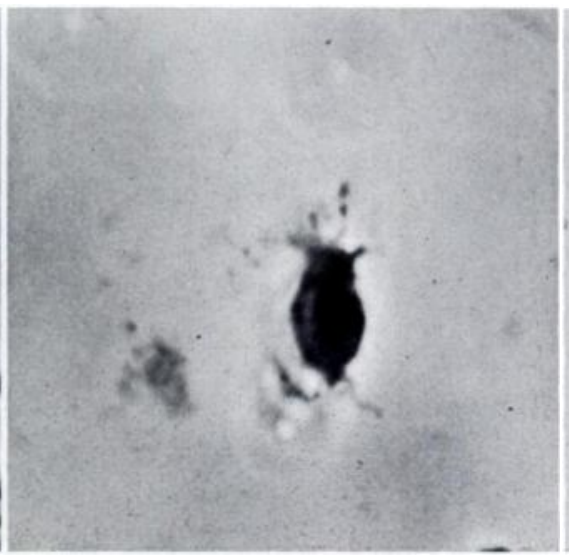

Fig. 4

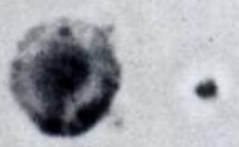

Fig. 5

Figure 3-Isolated bone cell suspended in culture medium. Phase conrast. $(\times 1200$.) Figure 4 -Isolated bone cell suspended in culture medium, shows uptake of trypan blue. Phase contrast. $(\times 1200$.) Figure 5-Photomicrograph showing uptake of trypan blue by one dead lymphocyte and two living lymphocytes excluding the dye. The cells are suspended in culture medium. Phase contrast. $(\times 900$.)

Absorption was performed (Wright, Hargreaves, Bansal, Bernstein and Hellström 1973) by incubation of 2 millilitres of undiluted serum with $2 \times 10^{8}$ lymphoid cells for sixty minutes at 37 degrees Celsius. After centrifugation, the serum was removed and stored at -20 degrees Celsius until used.

Specificity controls were done by absorbing some sera samples with lymphoid cells from "third party" Buffalo rats.

\section{RESULTS}

\section{Cellular in vitro experiments (Fig. 6)}

Mixed lymphocyte cultures between rats that differ at the major histocompatibility locus (lymphocytes from Lewis rats + lymphocytes from $\mathrm{BN}$ rats) gave, as expected, high and reproducible levels of lymphocyte stimulation (7898 C.P.M. \pm SE 556). On the other hand, mixed lymphocyte-bone cell cultures with the same strain combination (lymphocytes from Lewis rats + bone cells from $\mathrm{BN}$ rats) did not show lymphocyte stimulation in any of six consecutive experiments (49 C.P.M. \pm SE 7). These values were practically the same as those obtained in the control experiments in which lymphocytes+ lymphocytes or bone cells from the same rat strain were cultured (with no histocompatibility differences and, therefore, with no expected stimulation) (Fig. 6).

This suggests that bone cells, at least after the isolation procedure that was performed and under culture conditions used, did not stimulate allogeneic lymphocytes in vitro.

The possibility that isolated bone cells may have some inhibitory effect over lymphocyte stimulation was ruled out. Mixed lymphocyte cultures in which bone cells were added (lymphocytes from Lewis rats + lymphocytes and bone cells from BN rats) showed high levels of lymphocyte stimulation (7315 C.P.M. \pm SE $202)$ and no significant differences were found $(P>0 \cdot 50)$ with regular mixed lymphocyte cultures (lymphocytes from Lewis rats + lymphocytes from BN rats)

\section{Humoral cytotoxicity experiments}

(Fig. 7 and Table I)

Serum raised in Lewis rats with complete bone grafts

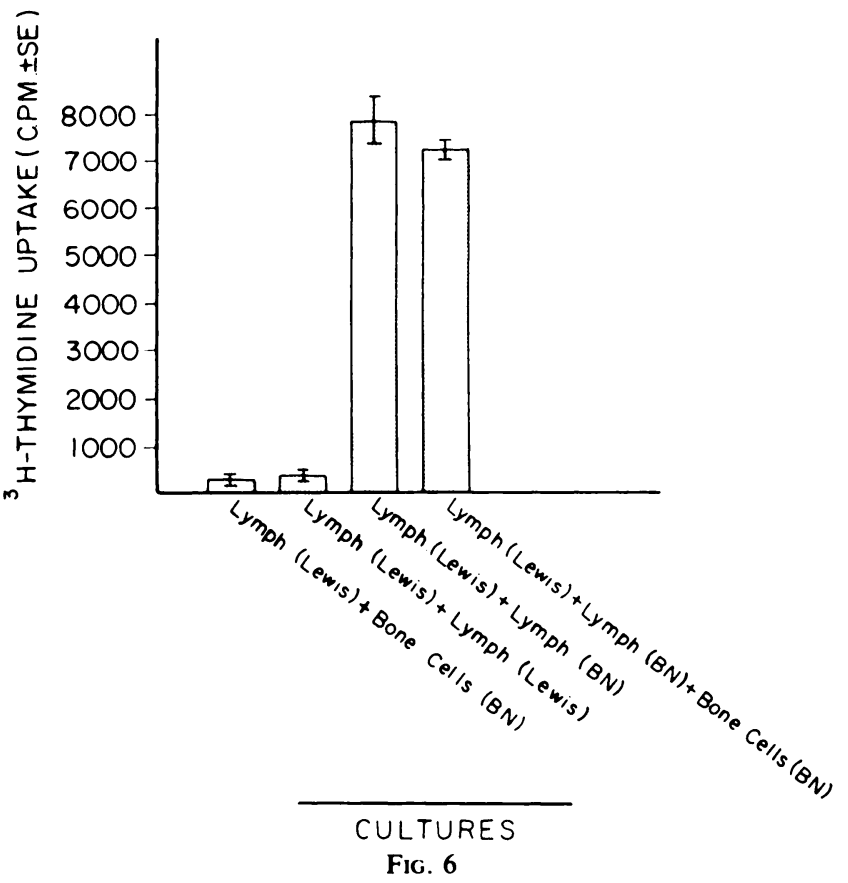

Mixed lymphocyte culture (MLC) and mixed lymphocyte-bone cell culture (MLBCC) results. Cultures were harvested after 120 hours after eighteen hours pulse with ${ }^{3} \mathrm{H}$-Thymidine. Values for ${ }^{3} \mathrm{H}$-Thymidine uptake represent the lymphocyte stimulation in each culture. Note that bone cells alone were incapable of stimulating allogeneic lymphocytes in vitro. Lymph.=lymphocytes; Lewis = Lewis rats; $B N=$ Brown Norway rats.

from BN rats (fifteen antisera from nine different grafted animals) showed $69 \pm$ SE 2 cytotoxic index over BN lymphocytes and $37 \pm$ SE 4 over BN bone cells $(P<0.001)$.

Serum raised in Lewis rats with bone grafts free of marrow from BN rats (twelve antisera from six different grafted animals) showed $60 \pm$ SE 5 cytotoxic index over BN lymphocytes and $31 \pm$ SE 3 over $B N$ bone cells $(P<0.001)$.

The specificity of these two groups of antisera was tested over "third party" lymphocytes and bone cells from Buffalo rats, and no significant cytotoxicity was found. 


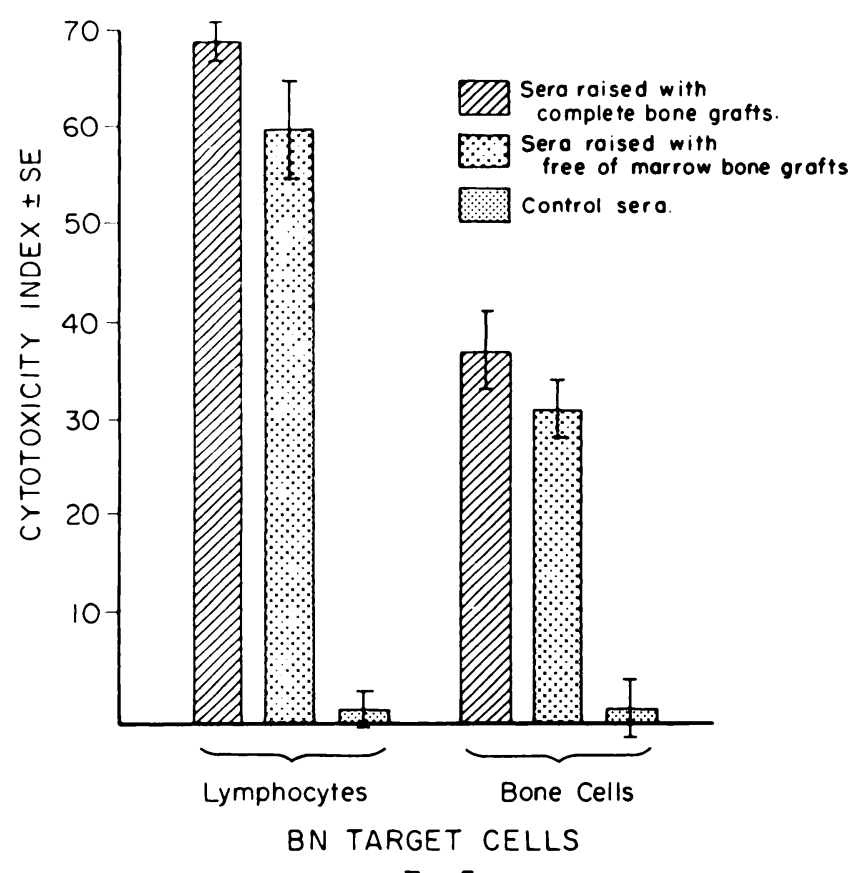

FIG. 7

Humoral cytotoxicity results. Sera raised with complete bone grafts or with free-of-marrow bone grafts gave positive cytotoxicity against either isolated bone cells or lymphocytes from the donor. Cytotoxicity activity was recorded as cytotoxicity index:

$$
\frac{\text { sample-control }}{100-\text { control }} \times 100 \text {. }
$$

These results indicate that bone cells share transplantation antigens with lymphocytes, but lower cytotoxic levels were found over bone cells using the same antisera.

\begin{abstract}
Absorption tests (Table II)
Absorption anlayses to determine further the identity of lymphoid and bone cell transplantation antigens were carried out.

Three different antisera samples, two raised with BN complete bone and one with BN free-of-marrow bone, were absorbed with BN lymphoid cells. Humoral cytotoxic indices over BN lymphocytes dropped to control levels after absorption (unabsorbed: 69, 67 and 65; absorbed: 3, 2 and 6 respectively). Also, when humoral cytotoxic indices were taken over $\mathrm{BN}$ bone cells, the values for the absorbed sera dropped dramatically (unabsorbed: 31, 49 and 29; absorbed: 13, 8 and 6 respectively). These results indicate that lymphoid and bone cells share antigens on their surface, at least to some extent, since the first were able to absorb antibodies with cytotoxic effect over the second.
\end{abstract}

\section{DISCUSSION}

It has been proposed that transplantation antigens responsible for the in vitro lymphocyte stimulation have a limited tissue distribution (Lane and Ling 1973), and

TABLE I

Comparison of Humoral Crtotoxictry Indices Obtained Against Isolated Bone Cells and Lymphocytes

Significance levels were calculated using the Student $t$ test

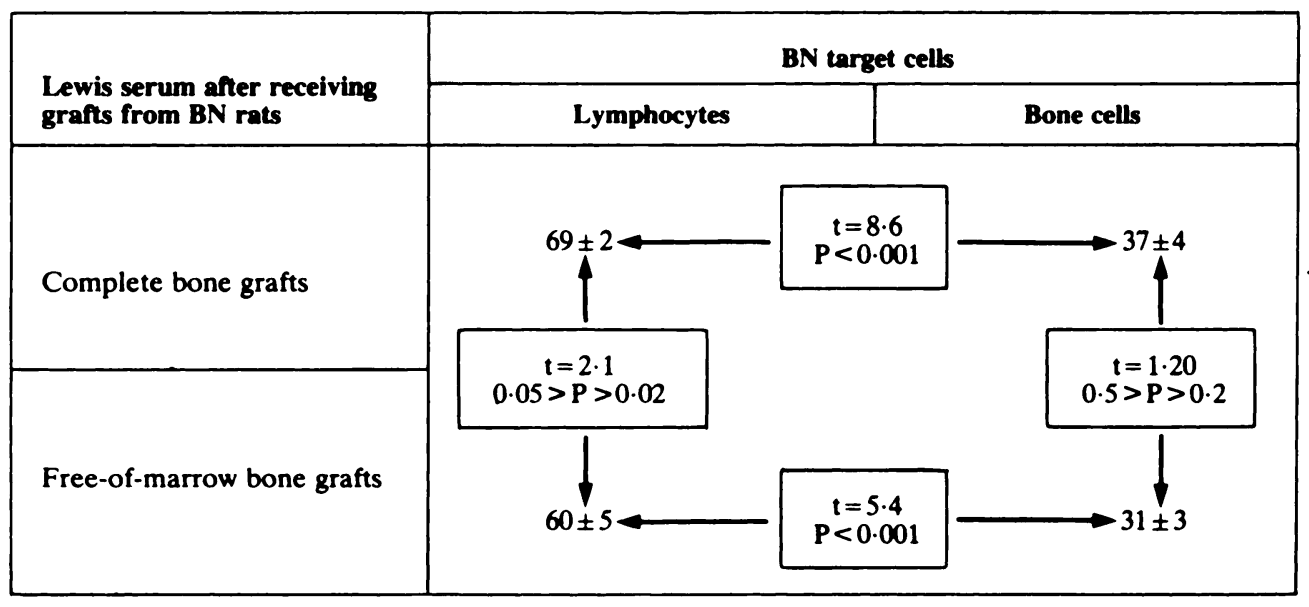

Control sera obtained from Lewis rats grafted with bone from Lewis or Fisher rats (twelve sera samples from five different rats) showed $0 \pm S E 2$ cytotoxic index over BN lymphocytes and $0 \pm$ SE 3 over BN bone cells.

Finally, the cytotoxic indices of serum raised in Lewis rats with BN complete bone and BN free-ofmarrow bone were compared (Table I). When lymphocytes were used as target cells, the differences in favour of the first were significant $(0.05>P>0.02)$, but if bone cells were the target, there was no significant difference $(0.5>P>0.2)$ between both groups. studies on the ability of cells other than lymphocytes to induce such stimulation have been reported. Fibroblasts (Main 1973), thyroid cells (Pulvertaft and Pulvertaft 1967) and brain cells (Lane, Jackson and Ling 1975) are incapable of stimulating allogeneic lymphocytes in vitro. On the other hand, epidermal cells (Main, Cochrum, Jones and Kountz 1971), endothelial cells (Vetto and Burger 1972), sperm cells (Levis and Whalen 1976) and recently chondrocytes (Gertzbein and Lance 1976) proved to be good stimulators. Neoplastic bone cells have also been tested (Vánky, Stjernswärd and Nilsonne 
TABLE II

Cytotoxic Reactions with Unabsorbed and Absorbed Sera Absorptions Performed With Lymphoid Cells from BN Rats *

\begin{tabular}{|l|l|c|c|}
\hline \multirow{2}{*}{} & \multicolumn{2}{c|}{ BN target cells } \\
\cline { 2 - 4 } & Serum & Lymphocytes & Bone cells \\
\hline $\begin{array}{l}\text { Lewis rat grafted } \\
\text { with BN complete } \\
\text { bone }\end{array}$ & Unabsorbed & 69 & 31 \\
\cline { 2 - 4 } & Absorbed & 3 & 13 \\
\hline $\begin{array}{l}\text { Lewis rat grafted } \\
\text { with BN complete } \\
\text { bone }\end{array}$ & Unabsorbed & 67 & 49 \\
\cline { 2 - 4 } $\begin{array}{l}\text { Lewis rat grafted } \\
\text { with BN bone } \\
\text { free-of-marrow }\end{array}$ & Absorbed & 2 & 8 \\
\cline { 2 - 4 } & Unabsorbed & 65 & 6 \\
\hline
\end{tabular}

- Cytotoxic activity was recorded as cytotoxicity index (see text). Note that absorption with lymphoid cells removes most of the activity for lymphocytes and bone cells.

1971; Han 1972), but the probable presence of tumourassociated antigens makes it difficult to extrapolate the results to normal bone cells.

The present studies suggest that isolated bone cells are incapable of stimulating allogeneic lymphocytes in vitro. This observation should be taken as preliminary due to the following possible variables in the experiment: 1) Inadequate bone cell concentration (due to the difficulty of obtaining more than one million isolated bone cells per millilitre). 2) Although 60 to 70 per cent of the isolated bone cells proved to be alive, it was not determined whether they were "metabolically alive", and this has been reported as essential to obtain lymphocyte stimulation (Schellekens and Eijsvoogel 1970). 3) The possible deleterious effect of collagenase and EDTA, used to isolate bone cells, on antigens responsible for lymphocyte stimulation.

Moreover, it may be possible that bone cells have a low antigen density in their membranes and, therefore, no sufficient "strength" to stimulate allogeneic lymphocytes in vitro.

Serologically defined (SD) transplantation antigens, demonstrated by the humoral cytotoxic test in this study, are thought to have a wide tissue distribution (Edidin 1972). Recently, several studies have been reported using intact cells isolated from different solid tissues to determine the presence of SD transplantation antigens on their cell surfaces. It was found that fibroblasts (Engelfriet, Heersche, Eijsvoogel and van Loghem 1966) endothelial cells (Vetto and Burger 1971), kidney cells (Perkins, Gantan, Siegel, Howell, Belzer and Kountz 1975), epidermal cells (Cooper and Lance 1971), sperm cells (Fellous and Dausset 1970), and chondrocytes (Elves 1974a; Malseed and Heyner 1976) were killed by, or were able to absorb, cytotoxic antibodies, showing cell membrane expression of those antigens.

Although there is serological evidence for the presence of transplantation antigens in bone (Elves 1974b; Langer, Czitrom, Pritzker and Gross 1975), no formal demonstration of SD transplantation antigens on bone cells has been reported.

The results of the humoral cytotoxicity experiments provide evidence for the presence of SD transplantation antigens on isolated bone cells. Sera raised with complete bone or with bone free of marrow were able to kill lymphocytes and isolated bone cells from the donor. These reactions proved to be immunologically specific, since control and "third party" reactions were negative. Quantitative differences in the cell-antigen expression between both cell lines were found, since cytotoxicity indices were significantly higher against lymphocytes than bone cells. Absorption studies confirmed a "share" of SD transplantation antigens, since lymphoid cells were able to absorb most of the antibodies with cytotoxic effect over bone cells. The remnant cytotoxicity that was found after absorption could be explained by the possible presence of differentiation or tissue-specific antigens on bone cells, as described for other cell lines, but there was no attempt to confirm this speculation.

The expression of lymphocyte stimulating antigens and SD transplantation antigens at the cell surface is genetically determined by a chromosomal region called $\mathrm{Ag}-\mathrm{B}$ in the rat and $\mathrm{HL}-\mathrm{A}$ in the human. Interest in these so-called "transplantation HL-A antigens" has been explosive in recent years due to the increasing evidence that they are in close relation with a great number of pathological conditions.

HL-A antigens play a fundamental role in the acceptance or rejection of transplanted foreign tissues (Van Rood, Blusse Van Oud Alblas, Keuning, Frederiks, Termijtelen, Van Hooff, Pena and Van Leeuwen 1975). Bone allotransplantation, between different individuals within the same species, elicits transplantation immunity as other tissues do (Chalmers 1959; Burwell, Gowland and Dexter 1963). Even freeze-dried bone grafts with weak antigenicity (Burwell 1976; Friedlaender 1976) seem to preserve transplanta- 
tion antigens able to generate an immune response (Urist, Mikulski and Boyd 1975), possibly due to persistence of those antigens on dead cells or cell debris.

However, the role of cellular transplantation antigens in the fate of bone grafts is far from clear (Elves 1975). In addition to being responsible for the production of "destructive" cytotoxic antibodies and lymphocytes, HL-A antigens trigger, under certain circumstances so far unclear, the production of a type of antibody called "blocking", since they tend to protect the graft from immune recognition or destruction (Carpenter, D'Apice and Abbas 1976). There is experimental evidence suggesting that this may be a factor (Bonfiglio and Jeter 1972; Langer et al. 1975) in bone transplantation. Further definition of the antigenic profile of bone cells, and interactions with the immune system may provide better understanding of this problem.

Association of HL-A antigens with particular diseases would imply distribution of transplantation antigens in those patients different from the normal population. Several diseases of bone and joint have recently been reported to be associated with increased frequency of a specific HL-A antigen, and probably more will be in the future. The strong association of HL-A B27 with spondylitis and related disorders is now well accepted. This antigen is present in approximately 95 per cent of patients with ankylosing spondylitis (Calin and Fries 1975).

Some abnormal developments of the lumbo-sacral spine may also be included in this group. Spina bifida occulta and asymmetry of the facet joints have been reported in association with specific $\mathrm{HL}-\mathrm{A}$ antigens (Amos, Ruderman, Mendell and Johnson 1975).

Frozen shoulder (Bulgen, Hazleman and Voak 1976) and arthritic psoriasis (Russel, Shultes and Kuban 1972) have been reported in association with particular HL-A antigens, supporting the theory of an immunogenetic origin of these conditions. The association of HL-A B27 with Reiter's disease and acute arthritis after established infections with Shigella, Yersinia or Salmonella (Brewerton 1975), and juvenile rheumatoid arthritis (Rachelefsky, Terasaki, Katz and Stiehm 1974) have also been reported.

Multiple myeloma (Bertrams, Kuwert, Böhme, Reis, Gallmeier, Wetter and Schmidt 1972), lymphomas, leukaemias, sarcomas and other solid tumours (Takasugi, Terasaki, Henderson, Mickey, Menck and Thompson 1973; Tarpley, Chretien, Rogentine, Twomey and Dellon 1975) have showed significant associations with specific HL-A antigens.

Although at present it is unclear how transplantation HL-A antigens relate to the resistance or susceptibility to neoplastic, auto-immune and infectious diseases in man, future developments in this field may throw light on the aetiology of these conditions.

Finally, recently presented observations suggest that tumour-associated transplantation antigens present in chemically induced sarcomas are modified or altered histocompatibility antigens present in normal cells (Bowen and Baldwin 1975; Invernizzi and Parmiani 1975). Better characterisation of bone cell surface histocompatibility antigens may provide further insight into the malignant transformation of the cells.

\section{REFERENCES}

Amos, D. B., Ruderman, R., Mendell, N. R., and Johnson, A. H. (1975) Linkage between HL-A and spinal development. Transplantation Proceedings, 7, Supplement 1, 93-95.

Bach, F. H., Bach, M. L., and Sondel, P. M. (1976) Differential function of major histocompatibility complex antigens in T-lymphocyte activation. Nature (London), 259, 273-281.

Bard, D. R., Dickens, M. J., Edwards, J., and Smith, A. U. (1974) Studies on slices and isolated cells from fresh osteoarthritic human bone. Journal of Bone and Joint Surgery, 56-B, 340-351.

Bertrams, J., Kuwert, E., Böhme, U., Reis, H. E., Gallmeier, W. M., Wetter, O., and Schmidt, C. G. (1972) HL-A antigens in Hodgkin's disease and multiple myeloma. Tissue Antigens, 2, 41-46.

Bonfiglio, M., and Jeter, W. S. (1972) Immunological responses to bone. Clinical Orthopaedics and Related Research, 87, 19-27.

Bowen, J. G., and Baldwin, R. W. (1975) Tumour-specific antigen related to rat histocompatibility antigens. Nature (London), $258,75-76$.

Brewerton, D. A. (1975) HL-A 27 and disease. Journal of Bone and Joint Surgery, 57-B, 247.

Bulgen, D. Y., Hazleman, B. L., and Voak, D. (1976) HL-A-B27 and frozen shoulder. Lancet, 1, 1042-1044.

Burwell, R. G. (1976) The fate of freeze-dried bone allografts. Transplantation Proceedings, 8, Supplement 1, $95-111$.

Burwell, R. G., Gowland, G., and Dexter, F. (1963) Studies in the transplantation of bone. VI. Further observations concerning the antigenicity of homologous cortical and cancellous bone. Journal of Bone and Joint Surgery, 45-B, 597-608.

Calin, A., and Fries, J. F. (1975) Striking prevalence of ankylosing spondylitis in "healthy" W27 positive males and females. New England Journal of Medicine, 293, 835-839.

Carpenter, C. B., D'Apice, A. J. F., and Abbas, A. K. (1976) The role of antibodies in the rejection and enhancement of organ allografts. Advances in Immunology, 22, 1-65.

Chalmers, J. (1959) Transplantation immunity in bone homografting. Journal of Bone and Joint Surgery, 41-B, 160-179.

Cooper, S., and Lance, E. M. (1971) A serological method for detecting the surface antigens of epidermal cells. Transplantation, $11,108-109$.

Edidin, M. (1972) The tissue distribution and cellular locations of transplantation antigens. In Transplantation Antigens, pp. 125-140. Ed. Kahan, B. D., and Reisfeld, R. A., New York: Academic Press.

Elves, M. W. (1974a) A study of the transplantation antigens on chondrocytes from articular cartilage. Journal of Bone and Joint Surgery, 56-B, 178-185.

Elves, M. W. (1974b) Humoral immune response to allografts of bone. International Archives of Allergy and Applied Immunology, 47, $708-715$.

Elves, M. W. (1975) Studies of the behaviour of allogeneic cancellous bone grafts in inbred rats. Transplantation, 19, 416-423.

Engelfriet, C. P., Heersche, J. N. M., Eljsvoogel, V. P., and van Loghem, J. J. (1966) Demonstration of leucocyte iso-antigens on skin fibroblasts by means of cytotoxic antibody test. Vox sanguinis, 11, 625-630. 
Fellous, M., and Dausset, J. (1970) Probable heploid expression of HL-A antigens on human spermatozoon. Nature (London), $225,191-193$.

Friedlaender, G. E. (1976) The antigenicity of preserved allografts. Transplantation Proceedings, 8, Supplement 1, 195-200.

Gertzbein, S. D., and Lance, E. M. (1976) The stimulation of lymphocytes by chondrocytes in mixed cultures. Clinical and Experimental Immunology, 24, 102-109.

Han, T. (1972) Blastogenic response of normal lymphocytes to cultured lymphoid cells and non-lymphoid neoplastic cells. Immunology, 23, 355-359.

Invernizzi, G., and Parmiani, G. (1975) Tumour-associated transplantation antigens of chemically induced sarcomata cross reacting with allogeneic histocompatibility antigens. Nature (London), 254, 713-714.

Lane, J. T., Jackson, L., and Ling, N. R. (1975) Lymphocyte stimulation with skin cells. A function of maturation. Transplantation, 19, $250-2.59$.

Lane, J. T., and Ling, N. R. (1973) Rat thymocytes-the allogeneic response and syngeneic effects in mixed cultures with tissue cells from various organs. Transplantation, 16, 602-609.

Langer, F., Czitrom, A., Pritzker, K. P., and Gross, A. E. (1975) The immunogenicity of fresh and frozen allogeneic bone. Journal of Bone and Joint Surgery, 57-A, 216-220.

Levis, W. R., and Whalen, J. J. (1976) Mixed cultures of sperm and leukocytes as a measure of histocompatibility in man. Science, 191, 302-304.

McDevitt, H. O., and Bodmer, W. F. (i974) HL-A, immune response genes, and disease. Lancet, 1, 1269-1275.

Main, R. K. (1973) In reference to Mardiney et al. (letter). Transplantation, 15, 247.

Main, R. K., Cochrum, K. C., Jones, M. J., and Kountz, S. L. (1971) DNA synthesis in mixed cultures of rat leukocytes and allogeneic dissociated skin cells. Proceedings of the National Academy of Sciences of the U.S.A., 68, 1165-1168.

Malseed, Z. M., and Heyner, S. (1976) Antigenic profile of the rat chondrocyte. Arthritis and Rheumatism, 19, $223-231$.

Muscolo, D. L., Kawai, S., and Ray, R. D. (1976) Cellular and humoral immune response analysis of bone-allografted rats. Journal of Bone and Joint Surgery, 58-A, 826-832.

Ottolenghi, C. E. (1972) Massive osteo and osteo-articular bone grafts. Clinical Orthopaedics and Related Research, 87, 156-164.

Palm, J. (1971) Immunogenetic analysis of Ag-B histocompatibility antigens in the rat. Transplantation, 11, 175-183.

Perkins, H. A., Gantan, Z., Siegel, S., Howell, E., Belzer, F. O., and Kountz, S. L. (1975) Reactions of kidney cells-with cytotoxic antisera: possible evidence for kidney-specific antigens. Tissue Antigens, 5, 88-98.

Pulvertan, R. J. V., and Pulvertant, I. (1967) Activation of lymphocytes. Journal of Clinical Pathology, 20, 795-805.

Rachelefsky, G. S., Terasaki, P. I., Katz, R., and Stiehm, E. R. (1974) Increased prevalence of W27 in juvenile rheumatoid arthritis. New England Journal of Medicine, 290, 892-893.

Russel, T. J., Shultes, L. M., and Kuban, D. J. (1972) Histocompatibility (HL-A) antigens associated with psoriasis. New England Journal of Medicine, 287, 738-740.

Schellekens, P. T. A, and Eijsvoogel, V. P. (1970)Lymphocyte transformation in vitro. III. Mechanism of stimulation in the mixed lymphocyte culture. Clinical and Experimental Immunology, 7, 229-239.

Takasugi, M., Terasaki, P. I., Henderson, B., Mickey, M. R., Menck, H., and Thompson, R. W. (1973) HL-A antigens in solid tumors. Cancer Research, 33, 648-650.

Tarpley, J. L., Chretien, P. B., Rogentine, G. N., Jun., Twomey, P. L., and Dellon, A. L. (1975) Histocompatibility antigens and solid malignant neoplasms. Archives of Surgery, 110, 269-271.

Tissot, R. G., and Cohen, C. (1972) Histocompatibility in the rabbit. Identification of the major locus. Tissue Antigens, 2, $267-279$.

Urist, M. R., Mikulski, A., and Boyd, S. D. (1975) A chemosterilized antigen-extracted autodigested alloimplant for bone banks. Archives of Surgery, 110, 416-428.

Vánky, F., Stjernswärd, J., and Nilsonne, U. (1971) Cellular immunity to human sarcoma. Journal of the National Cancer Institute, 46, $1145-1151$.

Van Rood, J. J., Blusse Van Oud Alblas, A., Keuning, J. J., Frederiks, E., Termijtelen, A., Van Hooff, J. P., Pena, A. S., and Van Leeuwen, A. (1975) Histocompatibility genes and transplantation antigens. Transplantation Proceedings, 7, Supplement 1, 25-30.

Vetto, R. M., and Burger, D. R. (1971) The identification and comparison of transplantation antigens on canine vascular endothelium and lymphocytes. Transplantation, 11, 374-377.

Vetto, R. M., and Burger, D. R. (1972) Endothelial cell stimulation of allogeneic lymphocytes. Transplantation, 14, $652-654$.

Wright, P. W., Hargreaves, R. E., Bansal, S. C., Bernstein, I. D., and Hellström, K. E. (1973) Allograft tolerance: presumptive evidence that serum factors from tolerant animals that block lymphocyte-mediated immunity in vitro are soluble antigen-antibody complexes. Proceedings of the National Academy of Sciences of the U.S.A., 70, 2539-2543. 